\title{
Efeito de diferentes meios nutritivos e fitorreguladores visando à otimização da calogênese de Annona mucosa (Jacq.)
}

BARBOZA, T.J.S.; LAGE, D.A.; MOSS, V. B.; SOUZA, C.A.; ALBARELLO, N.

Universidade do Estado do Rio de Janeiro, Departamento de Biologia Vegetal, Laboratório de Biotecnologia de Plantas (Labplan), R. São Francisco Xavier, 524. PHLC, sl. 509. CEP: 20.550-013. Maracanã, RJ - Brasil. labplan_uerj@yahoo.com.br

RESUMO: Annona mucosa é uma árvore frutífera da família Annonaceae, produtora de importantes metabólitos secundários de interesse medicinal, como lignanas, acetogeninas e alcaloides. A cultura in vitro de calos representa um importante recurso para a produção contínua de metabólitos, viabilizando a conservação da biodiversidade química e a obtenção controlada de material para estudos biológicos e fitoquímicos. O objetivo deste trabalho foi otimizar a produção de calos friáveis de $A$. mucosa, avaliando o efeito de diferentes meios nutritivos e fitorreguladores. Segmentos de folha e de hipocótilo de plântulas germinadas in vivo foram utilizados como explantes e inoculados nos meios de cultura MS, WPM e B5 suplementados com

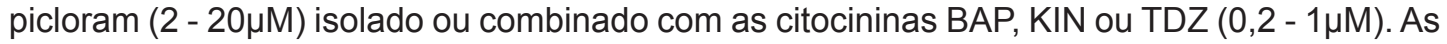
culturas foram mantidas a $26 \pm 2^{\circ} \mathrm{C}$, no escuro, com subcultivos mensais. A produção de calos foi avaliada por aferição do peso dos calos, após 90 dias. Em todos os tratamentos na presença da auxina picloram, o cultivo de hipocótilos resultou em maior porcentagem de formação de calos, sobretudo no meio de cultura WPM. A associação com TDZ produziu massa calogênica friável altamente proliferativa e ausente de oxidação, alcançando valores superiores àqueles obtidos em trabalhos prévios com a espécie. Os resultados viabilizam o uso do material em suspensões celulares e posterior caracterização fitoquímica para a exploração da produção in vitro de metabólitos da espécie.

Palavras-chave: Annonaceae, meios de cultivo, planta medicinal, produção de calos, reguladores de crescimento vegetal.

\begin{abstract}
Effect of different culture media and plant growth regulators for the optimization of callus induction of Annona mucosa (Jacq.). The Annona mucosa is a fruit tree of the Annonaceae family that produces a range of secondary metabolites of medicinal interest, such as lignans, acetogenins and alkaloids. The callus culture represents a renewable source of valuable medicinal compounds and controlled supply of material for biological and phytochemical studies. Therefore, this study was carried out to investigate the effects of three nutrient media, different concentrations of picloram and cytokinin types, in order to optimize the biomass yield and friability of calluses of $A$. mucosa. Leaf and hypocotyl segments from seedlings produced from in vivo seed germination were used as explants, which were inoculated in MS, WPM and B5 culture media supplemented with picloram $(2-20 \mu \mathrm{M})$ only or in addition to the cytokinins BAP, $\mathrm{KIN}$ or TDZ $(0,2-1 \mu \mathrm{M})$. Cultures were maintained at $26 \pm 2^{\circ} \mathrm{C}$ in the dark, with monthly subcultures. After 90 days, biomass production was evaluated. In all treatments, hypocotyl explants provided the highest percentage of callus formation, particularly in WPM. The association with TDZ produced highly proliferative friable callus, with no oxidation, reaching higher values than the previous works with this species. The results enable the use of the calluses produced in cell suspensions and the subsequent phytochemical characterization, in order to explore the in vitro production of metabolites of the species.
\end{abstract}

Keywords: Annonaceae, culture medium, medicinal plant, calli production, plant growth regulators. 


\section{INTRODUÇÃO}

Annona mucosa (Jacq.), anteriormente chamada pela sua sinonímia Rollinia mucosa (Jacq.) Bail. (Rainer, 2007), é conhecida popularmente como biribá e pertence à família Annonaceae, possuindo grande valor associado às suas características medicinais e alimentícias (Lorenzi, 2002).

A família Annonaceae apresenta diversos grupos de metabólitos com atividade medicinal, destacando-se acetogeninas, lignanas e alcaloides (Figueiredo et al., 1999; Reyes et al., 2002). Diversas acetogeninas foram identificadas e isoladas em A. mucosa (Gu et al., 1997; Chen et al., 1996b; Shi et al., 1997; Kuo et al., 2001; Liaw et al. 2003), além de diterpenos (Siebra et al., 2009), lignanas (Paulo et al. 1991; Chen et al., 1996a; Figueiredo et al., 1999; Reyes et al., 2002) e alcaloides isoquinolínicos (Chen et al., 1996a).

As acetogeninas têm apresentado respostas positivas em diferentes ensaios biológicos in vitro, tais como atividade leishmanicida e tripanocida (Waechter et al., 1999), larvicida contra Aedes aegypti (Dominguez-Martinez et al, 2003), atividade moduladora da resistência bacteriana (Costa et al., 2008), bactericida e antifúngica (Wiart, 2007). Entretanto, destaca-se o potencial antineoplásico dessas substâncias, sendo promissoras no tratamento de cânceres devido aos efeitos citotóxicos observados em linhagens tumorais e carcinomas diversos (Pettit et al., 1988; Shi et al., 1996; Shi et al., 1997; Gu et al., 1997, Kim \& Park, 2002).

Dentre as técnicas de culturas de tecidos vegetais, a calogênese resulta no cultivo de massas celulares, denominadas calos, podendo representar um sistema de produção contínua de substâncias bioativas in vitro de maneira sustentável (Andrade, 2002). Tal técnica tem sido amplamente explorada na produção de metabólitos de interesse medicinal de espécies nativas brasileiras (Simões et al, 2012; SimõesGurgel et al. 2012).

Calos com pouca coesão celular, sem constituição organogênica (competentes na produção de órgãos) são denominados como friáveis. Esta condição pode ser obtida por estímulos bióticos ou abióticos, sendo a constituição salínica do meio de cultura e o uso de fitorreguladores fatores cruciais no estabelecimento e manutenção dessas culturas (Iwase et al. 2013). Os calos friáveis são os mais indicados para o cultivo de células em suspensão, visando à produção de metabólitos secundários. Algumas estratégias como o uso de elicitores, substâncias mimetizadoras de estresse, podem favorecer a produção de substâncias in vitro nas culturas de calos, em concentrações superiores às obtidas em condições naturais ou substâncias diferentes às que são normalmente sintetizadas pelo vegetal (Patel \& krishnamurthy, 2013).

O estabelecimento da cultura de tecidos de $A$. mucosa foi iniciado em nosso laboratório, com resultados positivos para a micropropagação da espécie (Figueiredo et al., 2001). Em relação ao cultivo de tecidos não organizados, foram estabelecidas as culturas de calos produtores de lignanas e de células em suspensão (Figueiredo et al., 2000; 2003).

Tendo em vista a importância dos metabólitos presentes na espécie e da modulação de sua produção a partir da calogênese, o objetivo deste trabalho foi otimizar a produção de calos friáveis de $A$. mucosa, visando ao aumento da biomassa em relação ao protocolo inicialmente proposto para a espécie.

\section{MATERIAL E MÉTODOS}

\section{Material Botânico}

Sementes de Annona mucosa (Jacq.) foram obtidas por doação de propriedade privada localizada na cidade de Ananindeuá (Pará, Brasil), estando uma exsicata do material coletado depositada no Herbário da Universidade do Estado do Rio de Janeiro, sob registro HRJ11.478. As sementes foram germinadas in vivo em sementeiras de isopor, sendo mantidas em telado à temperatura ambiente $\left(28 \pm 2^{\circ} \mathrm{C}\right)$ e luminosidade natural (Figueiredo et al., 1999). Dois meses após a germinação, as plântulas obtidas foram utilizadas como fonte de explantes para o cultivo in vitro (Albarello et al., 2002). As plântulas foram descontaminadas com $\mathrm{NaOCl}$ a $2 \%$ por 20 minutos (hipocótilos) ou $1 \%$ por 15 minutos (folhas) acrescidos de $0,05 \%$ de Tween $80^{\circledR}$, conforme procedimento proposto por Figueiredo e colaboradores (2001).

Meios nutritivos e condições de cultivo Os explantes hipocotiledonares $(0,5$ $\mathrm{cm}$ de comprimento) e foliares $\left(0,8-1,0 \mathrm{~cm}^{2}\right)$ foram respectivamente inoculados em posição vertical e horizontal. Os explantes foliares foram colocados com a face abaxial em contato com o meio de cultura. Foram utilizadas três diferentes formulações de meios básicos para cultivo vegetal in vitro visando à indução de calos friáveis: MS (Murashige \& Skoog, 1962) e WPM (Lloyd \& McCown, 1980) suplementados 
com 30 g.L-1 de sacarose e B5 (Gamborg et al., 1968), suplementado com $20 \mathrm{~g} . \mathrm{L}^{-1}$ de sacarose. O fitorregulador principal para todos os meios de cultura foi o picloram (ácido 4-amino-3,5,6tricloropicolínico) nas concentrações de 2, 4, 10 ou $20 \mu \mathrm{M}$. O uso da auxina picloram foi avaliado em associação com as citocininas cinetina (KIN), benzilaminopurina (BAP) ou tidiazuron (TDZ), na proporção de $10 \%$ da concentração de picloram. Todos os meios foram solidificados com 8g.L-1 de ágar, com pH dos ajustado em 5,8 e a esterilização ocorreu a $121^{\circ} \mathrm{C}$ por 15 minutos.

Foram utilizados 20 explantes por tratamento hormonal, inoculados em frascos de vidro $(43 \times 45 \mathrm{~mm})$ vedados com tampas de polipropileno. As culturas foram mantidas em câmara de crescimento a $26 \pm 2^{\circ} \mathrm{C}$, no escuro. A cada 30 dias, o material foi subcultivado em meio de cultura com a mesma composição e transferido para frascos maiores $(65 \times 85 \mathrm{~mm})$. Após 90 dias de cultivo, os calos formados foram avaliados quanto à biomassa, por aferição dos pesos de matéria fresca e seca $\left(40^{\circ} \mathrm{C} / 24 \mathrm{~h}\right)$.

\section{Análise estatística}

Os resultados relacionados aos experimentos de cultivo in vitro foram submetidos à análise de variância de dados (ANOVA), em delineamento completamente casualizado. A diferença estatística para os tratamentos entre meios de cultura e concentrações de picloram foi indicada pelo teste de Tukey, ao passo que a adição de diferentes citocininas ao melhor tratamento obtido com picloram foi avaliada pelo teste de Dunnett, ambos ao nível de significância de 5\%.

\section{RESULTADOS E DISCUSSÃO}

\section{Indução de calogênese}

Em todos os tratamentos utilizados, os explantes hipocotiledonares produziram massas calogênicas pouco friáveis, onde eram observados grupos de aglomerados compactos de células com coloração variando de bege a marrom claro. Os explantes foliares, em sua maioria, não sofreram completa desdiferenciação de seus tecidos, apresentando ao final do terceiro mês de cultivo um aspecto de formação calogênica incompleta, sendo observada pouca massa sobre a nervura mediana dos explantes.

Dentre os explantes testados, os hipocótilos propiciaram as maiores médias de massa calogênica, tanto em relação à massa fresca quanto à seca, em comparação aos resultados obtidos com explantes foliares (Tabela 1). Os maiores valores de peso seco de calos provenientes de explantes hipocotiledonares $(0,189 \mathrm{~g})$ foram obtidos em meio WPM suplementado com a menor concentração de

TABELA 1. Produção de massa calogênica $(\mathrm{g})$ a partir de explantes hipocotiledonares e foliares de $A$. mucosa após 90 dias de cultivo, em diferentes meios básicos de cultura e concentrações da auxina picloram.

\begin{tabular}{cccccc}
\hline \multirow{2}{*}{$\begin{array}{c}\text { Meio de } \\
\text { cultura }\end{array}$} & Picloram & $(\mu \mathrm{M})$ & \multicolumn{3}{c}{ Tipo de explante } \\
\cline { 3 - 6 } & & Peso fresco & Peso seco & Peso fresco & Peso seco \\
\cline { 3 - 6 } & 0 & - & - & - & Folha \\
\hline \multirow{3}{*}{ MS } & 2 & $3,628 \pm 1,515^{*}$ & $0,151 \pm 0,042^{*}$ & $0,116 \pm 0,089$ & $0,031 \pm 0,019$ \\
& 4 & $2,445 \pm 0,554$ & $0,141 \pm 0,027^{*}$ & $0,739 \pm 0,873$ & $0,076 \pm 0,064^{*}$ \\
& 10 & $1,388 \pm 0,594$ & $0,096 \pm 0,035$ & $2,267 \pm 0,774^{*}$ & $0,114 \pm 0,025^{*}$ \\
& 20 & $1,635 \pm 0,930$ & $0,174 \pm 0,038^{*}$ & $1,949 \pm 0,879^{*}$ & $0,113 \pm 0,047^{*}$ \\
\hline \multirow{4}{*}{ B5 } & 0 & - & - & - & - \\
& 2 & $1,625 \pm 0,562$ & $0,090 \pm 0,028$ & $0,394 \pm 0,443$ & $0,062 \pm 0,042^{*}$ \\
& 4 & $2,652 \pm 0,836^{*}$ & $0,100 \pm 0,031$ & $1,426 \pm 0,916^{*}$ & $0,142 \pm 0,062^{*}$ \\
& 10 & $2,042 \pm 0,994$ & $0,088 \pm 0,032$ & $1,137 \pm 1,208$ & $0,069 \pm 0,036^{*}$ \\
\multirow{4}{*}{ WPM } & 20 & $1,867 \pm 0,607$ & $0,086 \pm 0,019$ & $0,533 \pm 0,481$ & $0,048 \pm 0,044$ \\
\hline & 0 & - & - & - & - \\
& 2 & $3,262 \pm 0,898^{*}$ & $0,189 \pm 0,111^{*}$ & $0,444 \pm 0,381$ & $0,093 \pm 0,040^{*}$ \\
& 10 & $3,579 \pm 1,157^{*}$ & $0,165 \pm 0,055^{*}$ & $0,284 \pm 0,204$ & $0,084 \pm 0,026^{*}$ \\
& 20 & $3,299 \pm 0,853^{*}$ & $0,165 \pm 0,040^{*}$ & $0,344 \pm 0,300$ & $0,075 \pm 0,028^{*}$ \\
& $3,380 \pm 0,728^{*}$ & $0,156 \pm 0,037^{*}$ & $0,355 \pm 0,392$ & $0,083 \pm 0,051^{*}$ \\
\hline
\end{tabular}

Os dados representam os pesos médios dos calos \pm desvio padrão.

(-) Ausência da formação de calos

(*) Em cada tratamento, dados de mesma coluna não diferem estatisticamente (Tukey 0,05 ).

Rev. Bras. PI. Med., Campinas, v.16, n.4, p.905-911, 2014. 
picloram $(2 \mu \mathrm{M})$, enquanto os calos provenientes de explantes foliares apresentaram maiores valores de peso seco $(0,142 \mathrm{~g})$ em meio B5 suplementado com $4 \mu \mathrm{M}$ de picloram (Tabela 1).

Em relação à formulação nutritiva, o meio WPM resultou em maior crescimento dos calos a partir de explantes hipocotiledonares, tanto em peso fresco quanto seco, com médias de $3,3803 \mathrm{~g}$ e $0,1692 \mathrm{~g}$, respectivamente. Para os explantes foliares, a composição que propiciou maior peso fresco foi a do meio MS, com média de $1,2683 \mathrm{~g}$, enquanto para o peso seco, o melhor resultado foi obtido com o uso do meio WPM, atingindo o valor médio de $0,0841 \mathrm{~g}$ (Figura 1).

Em estudo anterior visando à calogênese de $A$. mucosa, a auxina picloram mostrou-se mais eficiente na produção de calos em comparação a outras auxinas, como ANA e 2,4-D (Figueiredo et al., 2000) e outros fitorreguladores (Figueiredo et al., 2003). No presente trabalho, explantes submetidos a tratamentos sem este fitorregulador não produziram calos (Tabela 1). O picloram atua na modificação da parede celular vegetal de modo direto, na síntese ou degradação de componentes, ou de maneira indireta, induzindo a diferenciação e proliferação celular (Alayón-Luaces et al., 2012). Esta auxina tem se mostrado eficiente para a manutenção do crescimento de calos e estabelecimento de culturas de células em suspensão em várias espécies, em concentrações menores que outras auxinas (George et al., 2008; Ling et al., 2008).

O meio de cultura básico WPM possui uma formulação especialmente desenvolvida para o cultivo de espécies lenhosas, sendo normalmente utilizado como alternativa ao meio MS, por possuir composição salínica mais diluída em macronutrientes e maior disponibilidade de vitaminas. (Assis \& Teixeira, 1998; Grattapaglia \& Machado, 1998).
Considerando que o uso de WPM resultou nas melhores respostas com a menor concentração de picloram, este meio foi selecionado para a otimização do protocolo de calogênese, primeiramente proposto por Figueiredo e colaboradores (2000). Os resultados obtidos para os calos provenientes de explantes hipocotiledonares em meio WPM atingiram valores próximos ao dobro do peso de matéria fresca obtida em meio MS por aqueles autores, exigindo menor suplementação de picloram.

\section{Associação de diferentes citocininas no processo calogênico}

Os melhores tratamentos em relação ao meio nutritivo e concentração de picloram, quando associados a diferentes citocininas foram satisfatórios na promoção da completa friabilidade de calos em explantes hipocotiledonares (Tabela 2). $O$ tratamento que gerou melhores resultados para hipocótilos foi aquele em que o meio WPM foi suplementado com $2 \mu \mathrm{M}$ de picloram e $0,02 \mu \mathrm{M}$ de TDZ, resultando em peso seco médio de $0,159 \mathrm{~g}$, não diferindo estatisticamente do tratamento na ausência da citocinina. Para os explantes foliares, a melhor resposta foi obtida em meio MS suplementado com $10 \mu \mathrm{M}$ de picloram e $0,1 \mu \mathrm{M}$ de $\mathrm{KIN}$, com peso seco médio de $0,164 \mathrm{~g}$.

A maior friabilidade foi obtida em calos cultivados em meio contendo picloram e cinetina ou TDZ, a partir de explantes hipocotiledonares. Além da alta taxa proliferativa e friabilidade, os calos obtidos em associação ao TDZ não apresentaram oxidação, resposta apresentada em todos os demais tratamentos. Frações de cerca de $1 \mathrm{~g}$ de calos cultivados em associação à cinetina ou TDZ (Figura 2), puderam ser utilizadas para subcultivo e amplificação da cultura.

A aplicação de citocininas exógenas às
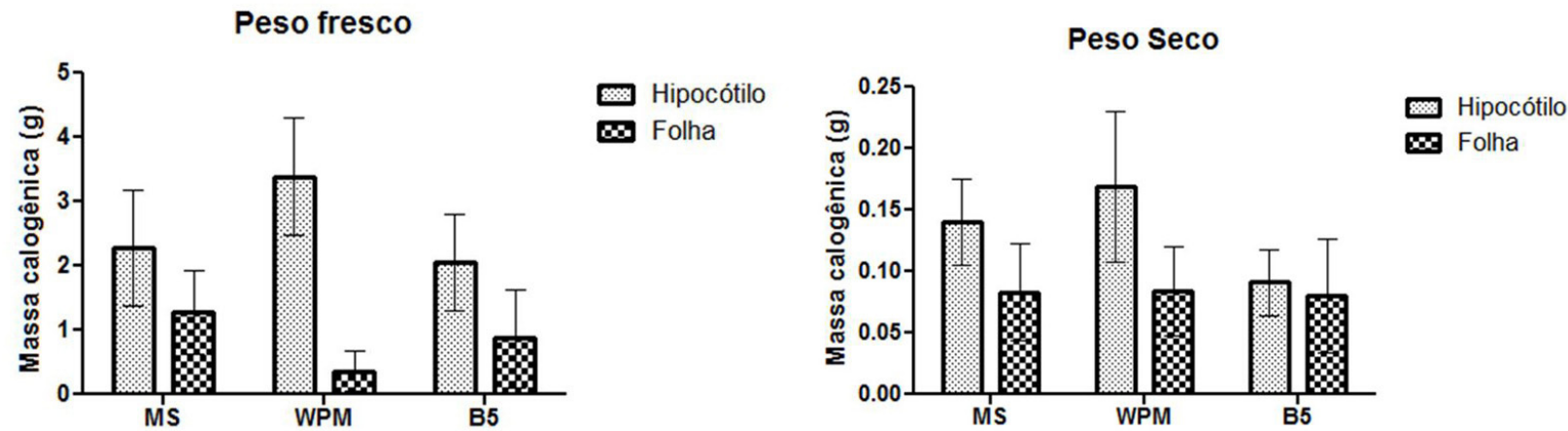

FIGURA 1. Valores médios da produção de massa calogênica total (g) em explantes hipocotiledonares e foliares de R. mucosa cultivados em diferentes meios nutritivos. 
TABELA 2. Produção de calos a partir de explantes hipocotiledonares e foliares de $A$. mucosa em meios nutritivos contendo picloram, suplementados ou não com citocininas.

\begin{tabular}{llll}
\hline Explante & Meio de Cultura Básico + picloram & Citocininas & Peso seco $(\mathrm{g})$ \\
\hline & & 0 & $0,189 \pm 0,111^{*}$ \\
Hipocótilo & WPM $+2 \mu \mathrm{M}$ & $0,02 \mu \mathrm{M} \mathrm{KIN}$ & $0,155 \pm 0,047^{*}$ \\
& & $0,02 \mu \mathrm{M}$ BAP & $0,082 \pm 0,058^{*}$ \\
& & 0 & $0,159 \pm 0,047^{*}$ \\
\hline \multirow{3}{*}{ Folha } & $\mathrm{MS}+10 \mu \mathrm{M}$ & $0,1 \mu \mathrm{M} \mathrm{KIN}$ & $0,114 \pm 0,025^{*}$ \\
& & $0,1 \mu \mathrm{M} \mathrm{BAP}$ & $0,164 \pm 0,065^{*}$ \\
& $0,1 \mu \mathrm{M} \mathrm{TDZ}$ & $0,03 \pm 0,012$ \\
\hline
\end{tabular}

(*) Para cada explante, valores em mesma coluna não diferem significativamente ao tratamento sem citocinina (Dunnett 0,05).
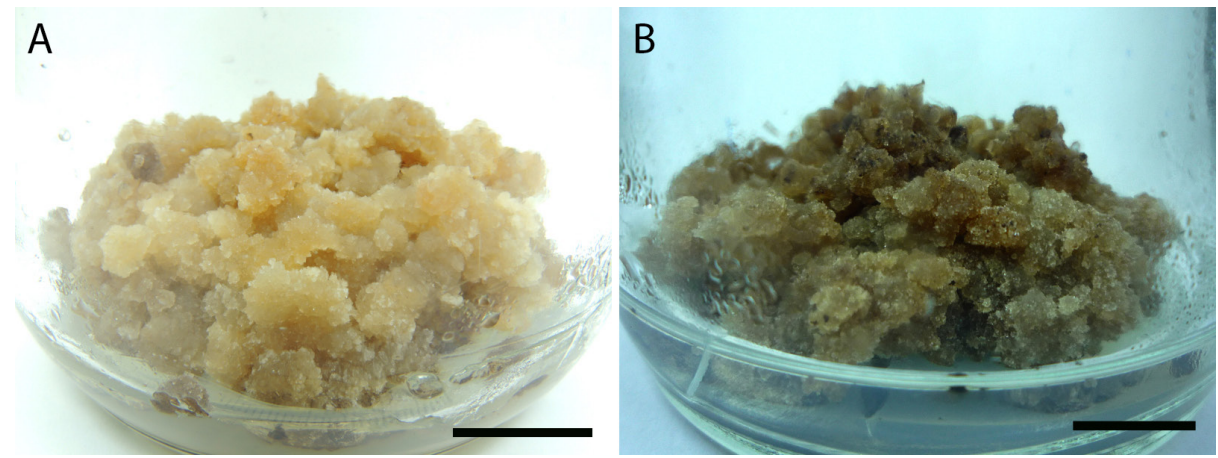

FIGURA 2 - Calos de origem hipocotiledonar cultivados em meio WPM suplementado com Picloram $(2 \mu \mathrm{M})$ e citocininas $(0,02 \mu \mathrm{M})$, após 12 meses de cultivo e subcultivos mensais. A - associação com TDZ; B - associação com KIN. Barras $=2 \mathrm{~cm}$.

culturas pode aumentar o conteúdo endógeno de diferentes tipos de citocininas, elevando a taxa proliferativa. Altas concentrações de KIN exógena em culturas de calos, após três meses de cultivo, podem aumentar o conteúdo total de citocininas endógenas (Pintos et al., 2002). O TDZ pode atuar na proliferação de calos de duas maneiras: com efeito de citocinina, na proliferação de diferenciação celular ou com ação similar à auxina, atuando na indução da competência embriogênica (Singh et al., 2003). Apesar de potente indutor de embriogênese somática quando utilizado isoladamente, O TDZ pode atuar como potente elicitor na produção de etileno endógeno, o que pode estimular o aumento de calos e a proliferação celular (Feng et al., 2012).

A oxidação dos explantes e culturas, bem como a baixa resposta morfogênica in vitro são as principais dificuldades no estabelecimento de protocolos eficientes para cultura de tecidos de espécies arbóreas. Tais problemas foram verificados no cultivo in vitro da espécie $A$. mucosa, pois estudos anteriores indicaram a necessidade de prétratamentos ou adição de substâncias antioxidantes ou adsorventes ao meio de cultura para reduzir o processo oxidativo, que leva à inviabilidade dos explantes (Figueiredo et al., 1999). Deste modo, a produção de calos ausentes de oxidação e com alta taxa proliferativa demonstra a eficiência do protocolo desenvolvido no presente trabalho, o que pode contribuir para a exploração de outros sistemas biotecnológicos e a investigação fitoquímica do material obtido.

\section{CONCLUSÃO}

A associação entre picloram e TDZ, em meio nutritivo WPM, constituiu o melhor protocolo para obtenção de calos friáveis, ausentes de oxidação, nas culturas provenientes de hipocótilos de A. mucosa. A possibilidade de manutenção das culturas em longo prazo, bem como a sua amplificação, tornam o protocolo promissor no avanço de estudos biotecnológicos e na exploração do potencial fitoquímico e medicinal da espécie.

\section{AGRADECIMENTO}

Às instituições de fomento FAPERJ, CAPES e CNPq pelo suporte financeiro e concessão de bolsas para a realização do trabalho. 


\section{REFERÊNCIA}

ALBARELLO, N. et al. Características morfológicas do fruto, da semente e da plântula da espécie medicinal Rollinia mucosa (Jacq.) Baill. - Annonaceae. Revista Brasileira de Farmácia, v.83, n.1, p.77-81, 2002.

ANDRADE, S.R.M. Princípios da cultura de tecidos vegetais. 58.ed., Planaltina: Embrapa cerrados, 2002. $16 \mathrm{p}$.

ASSIS, T.F. \& TEIXEIRA, S.L. Enraizamento de plantas lenhosas In: TORRES, A.C.; CALDAS, L.S.; BUSO, J.A. Cultura de tecidos e transformação genética em plantas. 1.ed. Brasilia: Ed. da Embrapa, v.1, 1998. p.331-353.

ALAYÓN-LUACES, P. et al. Compositional changes in cell wall polysaccharides from apple fruit callus cultures modulated by different plant growth regulators. Plant Science, v.186, n.1, p.169-175, 2012.

CHEN, Y.Y. et al. Isoquinoline alkaloids and lignans from Rollinia mucosa. Journal of Natural Prododucts, v.59, n.9, p.904-906, 1996a.

CHEN, Y.Y. et al. Epomusenins a and b, two acetogenins from fruits of Rollinia mucosa. Phytochemistry, v.42, n.4, p.1081-1083. 1996b.

COSTA, V.C.O. et al. Composição química e modulação da resistência bacteriana a drogas do óleo essencial das folhas de Rollinia leptopetala R.E. Fries. Revista Brasileira de Farmacognosia, v.18, n.2, p.245-248, 2008.

DOMINGUEZ-MARTINEZ, V.G. et al. Pupicidal activity of annonacin for Aedes argupti (L.) (Diptera: Culicidae). Folia Entomologica Mexicana, v.42, n.3, p.349-358, 2003.

FENG, B.H. et al. Cloning and expression of 1-aminocyclopropane-1-carboxylate oxidase cDNA induced by thidiazuron during somatic embryogenesis of alfalfa (Medicago sativa). Journal of Plant Physiology, v.169, n.1, p.176-182, 2012.

FIGUEIREDO, S.F.L. et al. Lignans from leaves, seedlings and micropropagated plants of Rollinia mucosa (Jacq.) Baill. - Annonaceae. Plant Cell, Tissue Organ Culture, v.56, n.1, p.121-124, 1999.

FIGUEIREDO, S.F.L. et al. Rollinia mucosa cell suspension cultures: establishment and growth conditions. Plant Cell, Tissue Organ Culture, v.63, n.1, p.85-92, 2000.

FIGUEIREDO, S.F.L. et al. Micropropagation of Rollinia mucosa (Jacq.) Baill. In Vitro Cellular and Developmental Biology, v.37, n.1, p.471-475, 2001.

FIGUEIREDO, S.F.L. et al. Rollinia mucosa (Jacq.) Bail.: establishment of callus culture and lignan production. Revista Cubana de Plantas Medicinales, v.8, n.3, 2003.

GAMBORG, O.L. et al. Nutrient requirements of suspension cultures of soybean root cells. Experimental Cellular Research, v.50, n.1, p.151-158, 1968.

GEORGE, E.F. et al. Plant propagation by tissue culture. 3.ed. Dordrecht: Springer, 2008. 520p.

GRATTAPAGLIA, D. \& MACHADO, M.A. Micropropagação In: TORRES, A.C.; CALDAS, L.S.; BUSO, J.A. Cultura de tecidos e transformação genética em plantas. 1.ed. Brasilia: Ed. da Embrapa, v.1, n.1, 1998. p.331353.

GU, Z.M. et al. Isolation of new bioactive annonaceous acetogenins from Rollinia mucosa guided by liquid chromatography/Mass spectrum. Bioorganic and Medicinal Chemistry, v.5, n.10, p.1911-1916, 1997.

IWASE, A. et al. Plant callus: mechanisms of induction and repression. The Plant Cell, v25, n.1, p.3159-3173, 2013.

KIM, J. \& PARK, E.J. Cytotoxic anticancer candidates from natural resources. Current Medicinal Chemistry, v.1, n.1, p.485-537, 2002.

KUO, R.Y. et al. Antiplatelet activity of N-methoxycarbonyl aporphines from Rollinia mucosa. Phytochemistry, v.57, n.1, p.421-425, 2001.

LIAW, C.H. et al. A novel constituent from Rollinia mucosa, Rollicosin, and a new approach to develop Annonaceous acetogenins as potential antitumor agents. Journal of Natural Products, v.66, n.2, p.279-281, 2003.

LING, O.S. et al. Establishment and optimisation of growth parameters for cell suspension cultures of Ficus deltoidea. American-Eurasian Journal of Sustainable Agriculture, v.2, n.1, p.38-49, 2008.

LLOYD, G. \& McCOWN, B. Commercially - feasible micropropagation of Mountain laurel, Kalmia latifolia, by use of shoot tip culture. Combined Proceedings of International Plant Propagators' Society, v.30, n.1, p.421-427, 1980.

LORENZI, H. Árvores brasileiras: manual de identificação e cultivo de plantas arbóreas nativas do Brasil. 4.ed. Nova Odessa: Plantarum, 2002. 368p.

MURASHIGE, T. \& SKOOG, F. A revised medium for rapid growth and bioassays with tobacco tissue cultures. Physiologia Plantarum, v.15, n.1, p.473479, 1962.

PATEL, H. \& KRISHNAMURTHY, R. Elicitors in plant tissue culture. Journal of Pharmacognosy and Phytochemistry, v.2, n.2, p.60-65, 2013.

PAULO, M.Q. et al. Lignans and other non-alkaloidal constituints from Rollinia mucosa, Annonaceae. Fitoterapia, v.62, n.2, p.150-151, 1991.

PETTIT, G.R. et al. Isolation and structure of rolliniastatin 1 from the South American tree Rollinia mucosa. Canadian Journal of Chemistry, v.65, n.1, p.1433-1435, 1988.

PINTOS, B. et al. Endogenous cytokinin levels in embryogenic and non-embryogenic calli of Medicago arborea L. Plant Science, v.163, n.1, p.955-960, 2002.

RAINER, H. Monographic studies in the genus Annona L. (Annonaceae): Inclusion of the genus Rollinia A.Sr.-Hil. Annalen des Naturhistorischen Museums in Wien, v.108, n.1, p.191-205, 2007.

REYES, R.E. et al. Lignans from leaves of Rollinia mucosa. Journal of Biosciences, v.57, n.1/2, p.29-32, 2002.

SHI, G. et al. Applying Mosher's Method to acetogenins bearing vicinal diols. The absolute configurations of Muricatetrocin $\mathrm{C}$ and Rollidecins $\mathrm{A}$ and $\mathrm{B}$, new bioactive acetogenins from Rollinia mucosa. Bioorganic and Medicinal Chemistry, v.4, n.8, p.1281-1286, 1996.

$\mathrm{SHI}, \mathrm{G}$. et al. Bioactive annonaceous acetogenins from Rollinia mucosa. Phytochemistry, v.45, n.4, p.719723, 1997.

SIEBRA, C.A. et al. Potencial antiinflamatório de Annona glabra, Annonaceae. Revista Brasileira de

Rev. Bras. PI. Med., Campinas, v.16, n.4, p.905-911, 2014. 
Farmacognosia, v.19, n.1, p.82-88, 2009.

SIMÕES, C. et al. Production of anthocyanins by plant cell and tissue culture strategies. In: ORHAN, I.E. Biotechnological production of plant secondary metabolites. 1.ed. Sharjah: Bentham, 2012. p.67-86.

SIMÕES-GURGEL, C. et al. Antibacterial activity of field-grown plants, in vitro propagated plants, callus and cell suspension cultures of Cleome rosea Vahl. Journal of Pharmacy Research, v.5, n.1, p.33043308, 2012.
SINGH, N.D. The effect of TDZ on organogenesis and somatic embryogenesis in pigeonpea (Cajanus cajan L. Millsp). Plant Science, v.164, n.1, p.341-347, 2003.

WAECHTER, A.I. et al. Leishmanicidal and Trypanocidal Activities of acetogenins Isolated from Annona glauca. Phytotherapy Research, v.12, n.1, p.541-544, 1999.

WIART, C. Goniothalamus species: a source of drugs for the treatment of cancers and bacterial infections. Evidence-Based Complementary and Alternative Medicine, v.4, n.3, p.299-311, 2007. 